Jurnal Kesehatan Masyarakat
http://journal.unnes.ac.id/nju/index.php/kemas

\title{
The Development and Initial Validation of the Indonesian HIV Social Stigma (I-HSS) Scale
}

\author{
Angga Wilandika ${ }^{\varpi}$, Diah Nur Indah Sari \\ Institute of Health Science 'Aisyiyah Bandung, Indonesia
}

\section{Article Info \\ Article History: \\ Submitted November 2019 \\ Accepted April 2020 \\ Published July 2020 \\ Keywords: \\ Human immunodefi- \\ ciency virus, commu- \\ nity, social stigma, scale \\ DOI \\ https://doi.org/10.15294/ \\ kemas.v16i1.22032}

\begin{abstract}
Human immunodeficiency virus (HIV) social stigma causes people living with HIV (PLWH) to cover their HIV status. Also, HIV social stigma makes PLWH afraid of seeking information and treatment. Thus, to eliminate the HIV social stigma, measuring tools are needed to obtain the social stigma of the disease. The study aims are to develop and assessed the validation of the instrument of HIV social stigma in society. The instrument was developed through a multi-stage process of item generations and psychometric test of the instrument consists of content validity, construct validity and reliability test. The HIV social stigma scale was distributed to a cross-sectional sample of people in several regions in West Java, Indonesia $(n=125)$. The final version of the I-HSS scales contained 25 items grouped into three dimensions (ignorance, prejudice, and discrimination) with a five-point Likert scale to score each item. Reliability was adequate for most dimensions (Cronbach's alpha $0,76-0,78$ ). Thus, the I-HSS scale were moderately correlated with one other $(r=0,52-0,84)$. Therefore, the I-HSS scale suggest a reliable and valid tool to measure social stigma toward people living with HIV in the community.
\end{abstract}

\section{Introduction}

The development of HIV infection as an endemic disease is closely related to the stigma of the disease. Stigma is defined as the act of labelling, discrediting, and discriminating against someone or a group of people on a characteristic that is considered different or deviating from the majority of society.

Monjok, Smesny, \& Essien (2009), said stigma is often associated with discrimination and has been described in many different ways. Furthermore, stigma related to knowledge, attitudes, and behaviour. Stigma is an act of giving a social sign that causes negative behaviour and aims to discredit someone (Evans-Lacko et al., 2010). Stigma refers to ignorance, prejudice, and discrimination.

The emergence of stigma in HIV was associated with the assumption that disease is dangerous and identical to sexual deviations and drug use (Earnshaw et al., 2015; Starks et al., 2014). This happens in the community so that views on HIV become negative and stigmatized. The HIV stigma becomes a burden that aggravates the handling of HIV infections.

The impact of HIV stigma from the community on people living with HIV (PLWH) has caused concern and fear among PLWH to seek treatment. As revealed by Nyblade, Stangl, Weiss, \& Ashburn (2009), stigma against HIV is a major obstacle in handling the disease. The stigma becomes an obstacle for PLWH in getting access to prevention, care and treatment services.

Besides, stigma has an impact on increasing the potential spread of HIV disease. Stigma has made PLWH reluctant to carry out an HIV tests. This stigma causes PLWH to cover up their positive HIV status, even make PLWH afraid of seeking information and 
treatment. The impact of HIV stigma can also lead to marginalized and isolated communities or groups (Bruce and Harper, 2011).

When a disease is stigmatized, it is hoped that various ways and strategies can suppress the development of stigmatization of the disease. However, there are times when the stigma that arises against HIV comes from a group of people with sufficiently high levels of education, economy and religious knowledge. Stigmatized diseases will make it difficult to accept the sufferer in the community.

Therefore, to reduce the stigma against HIV originating from the community, a measurement tool is needed to assess the social stigma. The aim of study is to develop an HIV social stigma scale and to evaluate the validity and reliability component of the instrument. The hypothesis of study is the scale developed has a good value of content validity and construct validity, as well as a good reliability value to measure the HIV social stigma in the community.

\section{Method}

The development and initial validation of an instrument requires a large number of respondents that represent the characteristics to be examined. The HIV social stigma scale, was distributed to a cross-sectional sample of people in several regions in West Java, Indonesia. Respondents come from residents over the age of 17 years and recorded as residents who already have a National Identity Card. The involvement of community members in this study was voluntary. A total of 125 people were involved in this study. Data collection was used non-random sampling with an online survey using Google Forms. The study was approved by the Health Research Ethics Committee at Institute of Health Science Aisyiyah Bandung.

The development of the I-HSS scale was carried out through three main stages: the development, instruments trial, and reporting of results for administering the tests (Haladyna and Rodriguez, 2013). An initial stage of the study was item generations based on the proposed theoretical framework and review literature. After that, the trial was conducted. In trials, the instruments that have been developed were administered to respondents and then were analysed to assess psychometric properties covering the content validity, construct validity, and reliability test.

I-HSS scale is an instrument developed in Indonesian. I-HSS scale is a questionnaire to measure people's views that negatively assess people or groups of people who have HIV/ AIDS. The stigma that arises in society refers to problems of knowledge (ignorance), negative attitudes (prejudice), and rejection behaviour (discrimination) (Evans-Lacko et al., 2010). I-HSS scale is a self-administered questionnaire and consisting of 25 items covering three dimensions of stigma: ignorance (seven items), prejudice (nine items), and discrimination (nine items). All items are negative questions with responses that are made on a five-point Likert type scale, ranging from 1 (totally agree) to 5 (totally disagree). The questionnaire also included several questions related to demographic characteristics and relevant information.

The statistical analysis was used software package SPSS version 22 (IBM Corp., Armonk, NY, USA). Reliability was measured by Cronbach's $\alpha$. Meanwhile, construct validity was used Pearson correlation to assess the score of each question with a total score of variables.

\section{Result and Discussion}

The sample consisted of 125 residents from several regions in West Java, Indonesia (46 men and 79 women) aged between 17 and 59 years $(M=29,03, S D=10,11)$. Most of them, $71(56,8 \%)$ were married, $50(40 \%)$ were single, and the other $4(3,2 \%)$ was widow. Almost half of them, $45(36,0 \%)$ were private employees; of the remainder, $37(29,6 \%)$ were students, 20 $(16,0 \%)$ were civil servants, $16(12,8 \%)$ were housewives, and 7 (5,6\%) were entrepreneurs.

The twenty five items were included in a content adequacy test to ensure content validity. All of the items in the I-HSS questionnaire were review by scientific experts from HIV/AIDS Service Unit at Gunung Jati Hospital, Cirebon. The results showed that all items on the I-HSS scale questionnaire have represented an aspect of the domain of the variable to be measured.

The mean and standard deviations of I-HSS scale items are given in Table 1. Result of the construct validity test (Table 1) indicated that the I-HSS scale was moderately correlated with another $(r=0,52-0,84)$. Overall items in I-HSS scale were valid. Meanwhile, the internal 
TabLe 1. Corrected item-total correlation of the I-HSS scale dimensions

\begin{tabular}{|c|c|c|c|}
\hline I-HSS Scale and Subscale Items & $\mathrm{r}$ & Mean & SD \\
\hline \multicolumn{4}{|l|}{ Ignorance (Knowledge Dimensions) } \\
\hline HIV is a curse, therefore sufferers must be shunned. & 0,56 & 2,03 & 1,09 \\
\hline PLHIV can transmit the disease by shaking hands or eating and drinking together. & 0,64 & 1,95 & 0,75 \\
\hline PLHIV tend to have many sexual partners. & 0.57 & 2.95 & 0.87 \\
\hline PLHIV are exposed to the virus due to immoral acts. & 0.65 & 2.58 & 0.99 \\
\hline I would not shake hands with someone if I knew that he/she had HIV. & 0.77 & 2.06 & 0.72 \\
\hline I prefer not to make physical contact with PLHIV. & 0.75 & 2.30 & 0.79 \\
\hline I am not willing to talk or chat with PLHIV. & 0.59 & 1.74 & 0.57 \\
\hline \multicolumn{4}{|l|}{ Prejudice (Attitude Dimensions) } \\
\hline PLHIV are sinners. & 0.75 & 2.10 & 0.67 \\
\hline PLHIV are immoral. & 0.75 & 1.95 & 0.55 \\
\hline PLHIV are disgusting. & 0.53 & 1.87 & 0.52 \\
\hline PLHIV violate religious teachings. & 0.69 & 2.48 & 0.87 \\
\hline PLHIV should be ashamed. & 0.72 & 2.20 & 0.78 \\
\hline PLHIV must be quarantined because they have a bad influence. & 0.57 & 2.21 & 0.65 \\
\hline Society will be better without a person who has HIV. & 0.52 & 3.15 & 1.14 \\
\hline Families of PLHIV should feel ashamed. & 0.54 & 2.10 & 0.83 \\
\hline I feel uncomfortable when I'm with person with HIV. & 0.73 & 2.57 & 0.76 \\
\hline \multicolumn{4}{|l|}{ Discrimination (Behaviour Dimensions) } \\
\hline I will not join an activity if there is a person who has HIV in that activity. & 0.80 & 2.08 & 0.75 \\
\hline PLHIV do not deserve to live in the same house as someone else because of disease. & 0.72 & 1.86 & 0.43 \\
\hline PLHIV must live with their fellow HIV sufferers. & 0.60 & 2.36 & 0.60 \\
\hline PLHIV must be excluded from activities in the community. & 0.76 & 1.92 & 0.52 \\
\hline PLHIV and their families should not become community leaders. & 0.78 & 2.08 & 0.52 \\
\hline PLHIV cannot be given a job because they can spread it to their co-workers. & 0.80 & 2.10 & 0.53 \\
\hline PLHIV must be fired from their jobs. & 0.68 & 1.98 & 0.42 \\
\hline PLHIV should not go to school with other people. & 0.84 & 1.97 & 0.40 \\
\hline PLHIV must receive their health services, may not join public health services. & 0.62 & 2.84 & 0.85 \\
\hline
\end{tabular}

$\mathrm{SD}=$ standard of deviation

consistency of I-HSS scale was adequate, with a Cronbach's alpha of 0,75 for the full questionnaire as well as for the each dimension of stigma: Ignorance $(\alpha=0,77)$, Prejudice $(\alpha=$ $0,76)$, and Discrimination $(\alpha=0,78)$.

HIV in the community has been a highly stigmatized disease. PLWH that is stigmatized faces a variety of harmful outcomes. Stigma has a negative impact on the health of PLWH(Molina and Ramirez-Valles, 2013). People with a high degree of stigma can suffer psychological distress and decrease in their health (Kamila and Siwiendrayanti, 2010). Then, people with a high degree of perceived stigma may be less likely to reveal their HIV status because they fear social rejection. These may threaten to compromise the value of antiretroviral therapy (ART) and thus affect the quality of life of PLWH (Gilbert and Walker, 2010).

HIV stigma has negative effects on the lives of infected people and is often cited as a barrier to HIV prevention and treatment (Arnold et al., 2014; Lindberg et al., 2014). Widespread prejudice, discrimination against PLWH, ignorance and misconceptions about how HIV is transmitted can be serious obstacles to HIV control programs. HIV prevention programs must engage more in community mobilization and literacy of rural communities in partnership with other agencies to rectify 
this (Deribew et al., 2010). There is consensus within the HIV prevention community that HIV stigma must be reduced and handle to eliminate the HIV epidemic.

By measuring a scale of HIV social stigma, the reduction strategy can be properly developed and addressed, the effectiveness of HIV stigma interventions can be appraised over monitoring and evaluation. Measuring community stigma toward PLWH may reveal a relevant predictor for participation in HIV prevention and treatment. Therefore valid and reliable instrument scales is important to mapping of HIV Stigma and to assess the extent and impact of HIV stigma (Lindberg et al., 2014).

The Indonesian HIV Social Stigma (I-HSS) scale encompasses three dimensions: dimension of information (ignorance), dimension of behaviours (prejudice) and dimension of actions (discrimination). These results demonstrated good reliability and validity for the total 25 items I-HSS scale as well as for the subscales. The construct validity scores of the overall items in the I-HSS scale ranged from $0.52-0.84$. Meanwhile, the internal consistency or reliability score for I-HSS scale is 0.75 . Although the sample size was small, this is a promising scale for measuring HIV social stigma in communities, especially in Indonesia.

\section{Conclusion}

HIV social stigma is multidimensional construct that covering three dimensions: ignorance, prejudice, and discrimination. The I-HSS scale and subscales demonstrated a valid and reliable measure for HIV social stigma in a community setting. Furthermore, a reliable measurement instrument can be developed to asses HIV social stigma in society adequately. The study has its own limitations. Our data were collected from a single province in Indonesia. Generalization of all over province in Indonesia still needs to be viewed with caution.

\section{Acknowledgment}

The author gratefully acknowledged a research grant from Institute of Health Science 'Aisyiyah Bandung.

\section{References}

Arnold, E.A., Rebchook, G.M., \& Kegeles, S.M., 2014. 'Triply Cursed': Racism, Homophobia and HIV-related Stigma are Barriers to
Regular HIV Testing, Treatment Adherence and Disclosure among Young Black Gay Men. Cult. Health Sex, 16, pp.710-722.

Bruce, D., \& Harper, G.W., 2011. Operating without a Safety Net: Gay Male Adolescents and Emerging Adults' Experiences of Marginalization and Migration, and Implications for Theory of Syndemic Production of Health Disparities. Heal. Educ. Behav, 38, pp.367-378.

Deribew, A., Abebe, G., Apers, L., Jira, C., Tesfaye, M., Shifa, J., Abdisa, A., Woldemichael, K., Deribie, F., \& Bezabih, M., 2010. Prejudice and Misconceptions about Tuberculosis and HIV in Rural and Urban Communities in Ethiopia: A Challenge for the TB/HIV Control Program. BMC Public Health, 10(400).

Earnshaw, V.A., Smith, L.R., Cunningham, C.O., \& Copenhaver, M.M., 2015. Intersectionality of Internalized HIV Stigma and Internalized Substance Use Stigma: Implications for Depressive Symptoms. J. Health Psychol. 20, pp.1083-1089.

Evans-Lacko, S., Little, K., Meltzer, H., Rose, D., Rhydderch, D., Henderson, C., \& Thornicroft, G., 2010. Development and Psychometric Properties of the Mental Health Knowledge Schedule. Can. J. Psychiatry, 55, pp.440-448.

Gilbert, L., \& Walker, L., 2010. 'My Biggest Fear was that People Would Reject Me Once They Knew My Status': Stigma As Experienced by Patients in An HIV/AIDS Clinic in Johannesburg, South Africa. Health Soc. Care Community, 18, pp.139-146.

Haladyna, T.M., \& Rodriguez, M.C., 2013. Developing and Validating Test Items. Taylor \& Francis.

Kamila, N., \& Siwiendrayanti, A., 2010. Perceptions of People Living with HIV and AIDS of The Role of Peer Support Groups. KEMAS J. Kesehat. Masy, 6.

Lindberg, M.H., Wettergren, L., Wiklander, M., Svedhem-Johansson, V., \& Eriksson, L.E., 2014. Psychometric Evaluation of The HIV Stigma Scale in a Swedish Context. PLoS One, 9, pp.e114867.

Molina, Y., \& Ramirez-Valles, J., 2013. HIV/AIDS Stigma: Measurement and Relationships to Psycho-behavioral Factors in Latino Gay/ Bisexual Men and Transgender Women. AIDS Care, 25, pp.1559-1568.

Monjok, E., Smesny, A., \& Essien, E.J., 2009. HIV/ AIDS-Related Stigma and Discrimination in Nigeria: Review of Research Studies and Future Directions for Prevention Strategies. 
Afr. J. Reprod. Health, 13.

Nyblade, L., Stangl, A., Weiss, E., \& Ashburn, K., 2009. Combating HIV Stigma in Health Care Settings: What Works?. J. Int. AIDS Soc. 12(15).
Starks, T.J., Payton, G., Golub, S.A., Weinberger, C.L., \& Parsons, J.T., 2014. Contextualizing Condom Use: Intimacy Interference, Stigma, and Unprotected Sex. J. Health Psychol, 19, pp.711-720. 